\title{
Comparison of FTAI and Natural Service Breeding Programs on Beef Cow Reproductive Performance, Program Cost and Partial Budget Evaluation
}

\author{
Herbert Lardner ${ }^{1}$, Daalkhaijav Damiran ${ }^{1} \&$ Kathy Larson ${ }^{2}$ \\ ${ }^{1}$ Department of Animal and Poultry Science, University of Saskatchewan, Saskatoon, SK, Canada \\ ${ }^{2}$ Department of Agricultural and Resource Economics, University of Saskatchewan, Saskatoon, SK, Canada \\ Corresponding author: Herbert Lardner, Department of Animal and Poultry Science, University of Saskatchewan, \\ Saskatoon, Saskatchewan, S7N 5A8, Canada. E-mail: bart.lardner@usask.ca
}

Received: June 27, 2020 Accepted: August 1,2020 Online Published: August 15, 2020
doi:10.5539/jas.v12n9p1
URL: https://doi.org/10.5539/jas.v12n9p1

The research is supported by Saskatchewan Agricultural Demonstration of Practices and Technologies \#20120423.

\begin{abstract}
The study compared a natural-service breeding (NSB) program to a single fixed-time artificial insemination (FTAI) program on beef cow reproductive efficiency, breeding costs and partial budget evaluation. Eighty Black Angus lactating beef cows (5-6 yrs of age; $n=80$; $\mathrm{BW}=599.4 \pm 78.6 \mathrm{~kg}$ ) were randomly assigned by age, days postpartum to either FTAI (FTAI cow) or NSB (NSB cow) breeding program. The FTAI cows received a CIDR for $7 \mathrm{~d}$ and $100 \mu \mathrm{g}(2 \mathrm{~mL})$ i.m. injection of $\mathrm{GnRH}$, following this $25 \mathrm{mg}(5 \mathrm{~mL})$ i.m. of $\mathrm{PGF}_{2 \alpha}$ i.m. with CIDR removed. Then a second $25 \mathrm{mg}(5 \mathrm{~mL})$ i.m. injection of $\mathrm{GnRH}$ approximately $66 \mathrm{~h}(\mathrm{~d} \mathrm{10})$ after initial injection to ensure luteal regression, and artificially inseminated with semen by a trained technician. The NSB cows were exposed to bulls at a bull:cow ratio of 1:25 for a $63 \mathrm{~d}$ breeding season. Results indicated that a NSB program can be a lower cost ( $\$ 85$ vs. $\$ 123)$ compared to FTAI program on a per cow basis. If improvements in conception rate, calf weaning rate, and total $205 \mathrm{~d}$ adjusted wean weights are incorporated, a partial budget analysis reveals FTAI can increase net profit by $\$ 284$ per cow.
\end{abstract}

Keywords: artificial insemination, beef cow, breeding cost, breeding program, estrous synchronization, reproductive efficiency

\section{Introduction}

In a commercial ranch setting in western Canadian, the predominant breeding system for beef producers is natural service breeding (NSB). However, fixed timed artificial insemination (FTAI) programs are widely used as an alternative reproductive management tool in beef and dairy operations (Meneghetti et al., 2009). Artificial insemination (AI) has been available as a technology for more than 70 years, with its use primarily in the dairy industry. A past USA publication reported that only $6 \%$ of beef cattle producers use AI and/or estrus synchronization in their herds (Parish \& Riley, 2011), and many of these operations are from the purebred sector. In western Canada, results from the 2019 cow-calf management adoption rates reported that artificial insemination was used by only $18 \%$ of producers surveyed, while estrus synchronization was used by only $11 \%$ of respondents (BsCRC, 2019).

Fixed-time artificial insemination (FTAI) programs can be favorable to beef producers because they reduce time and labor required for estrus detection and allow for integration of superior genetics. One of the primary deterrents for adoption of FTAI is the perceived cost to the cattle operation (Parish \& Riley, 2011). The low adoption rates may be due to several reasons. Firstly, compared to natural breeding, FTAI requires more intense knowledge and management, and increased investment in labour, facilities, equipment, semen, estrous synchronization drugs, and animal handling. With limited information available on FTAI compared to NSB in western Canada, a comparison of these breeding programs can provide results on conception, calf performance and cost. Most programs available to synchronize estrus in cows or heifers will use prostaglandin $\mathrm{F}_{2 \alpha}\left(\mathrm{PGF}_{2 \alpha}\right)$ as 
a component of the program to induce regression of the corpus lutea (CL), which leads to follicular maturation, estrus, and ovulation. Using a controlled intravaginal drug-releasing (CIDR $®)$ device or feeding melengestrol acetate $(M G A \circledR)$ is the basis for many timed AI (TAI) programs (Martinez et al., 2002). Most synchronization protocols typically recommend a CIDR be inserted in the vagina for a 7-d period (Lucy et al., 2001). The use of GnRH occurs two ways in timed AI protocols, early in protocols to generate some control over ovarian follicular wave development and/or later in protocols for ovulatory induction at or around the time of artificial insemination (Pursley et al., 1997). The objectives of this study were to compare a natural service breeding program and a CIDR plus GnRH-PGF $2 \alpha$ synchronization protocol on beef cow reproductive performance, calf performance, program costs and partial budget analysis.

\section{Materials and Methods}

\subsection{Site and Breeding Protocol}

The study was conducted at the Termuende Research Ranch of the Western Beef Development Centre (WBDC) located near Lanigan, Saskatchewan, Canada (lat. $51^{\circ} 51^{\prime} \mathrm{N}$, long. $105^{\circ} 02^{\prime} \mathrm{W}$ ). The WBDC research facility follows typical breeding and nutrition management practices of western Canadian cow-calf operations, as described elsewhere (Kelln et al., 2011; Krause et al., 2013; Lardner et al., 2014; Damiran et al., 2016, 2018). Based on days postpartum, 80 Black Angus multiparous beef cows $(5-6 \mathrm{yr}$ of age, $\mathrm{BW}=599.4 \pm 78.6 \mathrm{~kg}, \mathrm{BCS}=$ $3.0 \pm 0.2)($ mean $\pm S D)$ were selected from a herd of 300 cows. Selected cows were paired by days postpartum, age and body weight (BW) and were assigned to 1 of 2 treatments (programs) $(n=40 /$ treatment): (1) a $7 \mathrm{~d}$ CO-Synch + CIDR (FTAI); (2) a natural-service breeding (NSB) program (Figure 1).

\section{7 d CO-Synch + CIDR and Timed AI protocol (FTAI)}

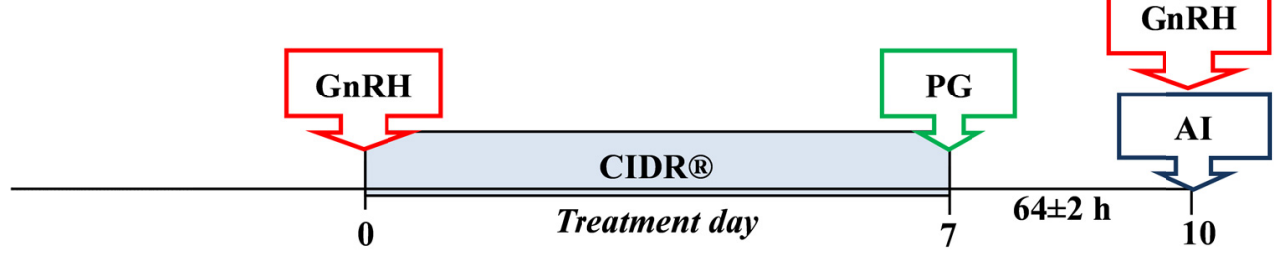

Figure 1. Treatment schedule for cows managed in $7 \mathrm{~d}$ CO-Synch + controlled internal drug release CIDR (TAI) protocol. Cows in 7-d CO-Synch received CIDR insertion and were administered gonadotropin-releasing hormone (GnRH; $100 \mu$ g, i.m., Cystorelin, Merial, Duluth, GA) on d 0, prostaglandin $\mathrm{F}_{2 \alpha}\left(\mathrm{PGF}_{2 \alpha} ; 25 \mathrm{mg}\right.$., i.m., Lutalyse, Pfizer Animal Health, New York, NY) on d 7, and GnRH and fixed-time AI (FTAI) $66 \mathrm{~h}$ after $\mathrm{PGF}_{2 \alpha}$ administration

Cows assigned to NSB program were exposed to bulls that passed a breeding soundness evaluation at a bull:cow ratio of 1:25 for a $63 \mathrm{~d}$ breeding season (June 24 to August 26, 2013). Cows assigned to the $7 \mathrm{~d}$ estrous synchronization + fixed-time AI (Co-Synch + CIDR) protocol received an intravaginal progesterone releasing device (CIDR) (d 0) (CIDR, Pfizer Animal Health, NewYork, NY), and $100 \mu \mathrm{g}(2 \mathrm{~mL})$ of gonadotropin-releasing hormone (GnRH; Cystorelin, Merial, Duluth, GA; i.m.) at CIDR insertion. Seven days (d 7) following CIDR insertion, cows were administered $25 \mathrm{mg}(5 \mathrm{~mL})$ of dinoprost tromethamine $\left(\mathrm{PGF}_{2 \alpha}\right.$; Lutalyse, Pfizer Animal Health, NewYork, NY; i.m.) and the CIDR inserts were removed. Fixed time AI program cows then received a second $25 \mathrm{mg}(5 \mathrm{~mL})$ i.m. injection of $\mathrm{GnRH} \sim 66 \mathrm{~h}(\mathrm{~d} 10)$ after the initial injection to ensure luteal regression (Figure 1). Cows were artificially inseminated (July 20 2013) by an experienced AI technician using semen from six purebred Angus AI sires ranging from $\$ 20$ to $\$ 40$ per straw (avg. $\$ 26.60$ per straw). Six days following AI, cows were exposed to a cleanup bull tested by a trained veterinarian for disease and fertility using a bull:cow ratio of 1:40 (assume $50 \%$ of cows conceive by AI, so required number of clean-up bulls decrease by $50 \%$ ( $40 \times$ $50 \%=20$ cows to breed), for a $47 \mathrm{~d}$ breeding season. Bull access had FTAI start $26 \mathrm{~d}$ later than NSB. All animals used in this study were cared for following the guidelines of the CCAC (2009).

\subsection{Animal Management}

During the breeding season and until pregnancy diagnosis in October, cows within each program were managed on mixed [crested wheatgrass (Agropyron cristatum (L.) Gaertn.; smooth bromegrass (Bromus inermis Leyss.); Kentucky bluegrass (Poa pratensis L.)] grass $(56.5 \% \mathrm{TDN} ; 12.5 \% \mathrm{CP})$ pasture. From pregnancy diagnosis to calving, the cows were managed as a single group grazing swathed barley $(69.3 \% \mathrm{TDN} ; 10.8 \% \mathrm{CP})$ from 
November to February, followed by drylot feeding free choice grass-legume hay $(86.6 \% \mathrm{DM} ; 58.5 \%$ TDN; $9.7 \%$ CP) with a daily supplemented range pellet $(2.7 \mathrm{~kg} / \mathrm{d} ; 79.5 \% \mathrm{TDN} ; 13.6 \% \mathrm{CP})$ from February to May. The winter and calving diets were designed to meet NRC (2000) protein and energy requirements for pregnant beef cows used in the current study. All cows had ad libitum access to a commercial 1:1 mineral supplement (Right Now Bronze, Cargill Nutrition) that contained $11.5 \% \mathrm{Ca}, 10 \% \mathrm{P}, 1 \% \mathrm{Mg}, 5.8 \% \mathrm{Na}, 200 \mathrm{ppm} \mathrm{I}, 4900 \mathrm{ppm} \mathrm{Fe}$, $2000 \mathrm{ppm} \mathrm{Cu}, 5000$ ppm Mn, 5000 ppm Zn, 20 ppm Co, 50 ppm Fl, 500000 IU/kg Vitamin A (min), 50000 $\mathrm{IU} / \mathrm{kg}$ Vitamin D3 (min) and $2500 \mathrm{IU} / \mathrm{kg}$ Vitamin E (min), and cobalt-iodized salt (99\% NaCl, 39\% Na, $100 \mathrm{mg}$ $\mathrm{Co}$, and $150 \mathrm{mg} / \mathrm{kg} \mathrm{I})$ throughout the year. Throughout the management period all cows had access to water in portable troughs.

\subsection{Animal Measurements}

During pregnancy diagnosis, cow body weight was corrected for conceptus gain using the following equation from NRC (2000):

$$
\text { Conceptus weight }(\mathrm{kg})=(\text { Calf birth weight } \times 0.01828) \times \mathrm{e}^{[(0.02 \times t)-(0.0000143 \times \mathrm{x} \times \mathrm{t})]}
$$

where, $t$ is the days of pregnancy. Date of conception was determined by subtracting $282 \mathrm{~d}$ from the calving date (DeRouen et al., 1994). Cow body condition score (BCS) was determined by a trained technician at pregnancy diagnosis using the Scottish scale of 1 to $5(1=$ emaciated to 5 = grossly fat; Lowman et al., 1976).

\subsection{Pregnancy Diagnosis}

Pregnancy was diagnosed $90 \mathrm{~d}$ after FTAI via rectal palpation by a veterinarian. Artificial insemination conception rates were determined based on calving date, with d from FTAI (July 20, 2013) to calving calculated at $282 \mathrm{~d}$ based on average gestation lengths reported in previous literature for AI sires (Larson et al., 2006). Overall pregnancy percentage was determined as the percentage of cows that were pregnant from either FTAI or natural service during the breeding season.

\subsection{Reproductive Performance}

Pregnancy rate was calculated as the proportion of cows exposed to bulls or artificially inseminated that were confirmed pregnant by a veterinarian by palpation. Cows displaying signs of estrus after a positive pregnancy check were re-palpated, and if found to be non-pregnant, the original conception was listed as an abortion. Calving percentage was calculated by dividing the number of calves born by the number of cows exposed (either FTAI or NSB) according to Reiling (2011). Calf birth weight was collected within $24 \mathrm{~h}$ of birth, and calving span or length of calving was calculated as the difference between the last and first calving day of live birth within each program. Calving distribution or percent of females calving in each $21 \mathrm{~d}$ interval was also calculated for each program. Calves born alive was estimated as the proportion of calves alive at birth. Weaning percentage was calculated as the number of calves weaned divided by the number of females exposed according to Reiling (2011). Calves were weaned on October 2, 2014, and weaning weights (WW, kg) were measured. All calf 205-d adjusted weaning weights $\left(\mathrm{WW}_{205 \mathrm{~d} \text { adjust }}\right)$ were also calculated. Data were used to determine breeding program effects on cow reproductive performance and weaned calf performance.

Calf cumulative weaning weight (CWW) or calf cumulative $205 \mathrm{~d}$ adjusted weaning weight was determined as follows: $\mathrm{CWW}\left(\mathrm{CWW}_{205 \mathrm{~d} \text { adjust. }}\right), \mathrm{kg} /$ program $=\sum \mathrm{WW}_{i}$, where, $\mathrm{WW}_{i}$ is the weaning weight (or $205 \mathrm{~d}$ adjusted weaning weight) of each calf in the breeding program.

\subsection{Economic Analysis}

A partial-budget analysis was calculated and used to compare the FTAI and NSB programs following the approach used by Parish and Riley (2011). Partial budget analysis is a methodology to assess changes in profit arising from a change in production practices (Tigner, 2018). Partial budget analysis only considers the parts of the business that change as the result of a practice being adopted. The disadvantages (increased costs and reduced revenues) expected to result from a new practice's implementation are subtracted from the expected advantages (decreased costs and increased revenues) resulting from implementation to generate the net change from the newpractice being considered. In the analysis, FTAI is the alternative program considered, therefore advantages from FTAI adoption allowing for increase in revenue and reduced costs were assumed to be: increase in total $\mathrm{kg}$ weaned, improvement in wean percentage, reduced breeding bulls required and reduced number of replacement females required. Disadvantages from FTAI adoption that may decrease revenue and increase costs, were assumed to be: cost of FTAI drugs and CIDR, semen costs, AI technician, additional labour and infrastructure requirements, reduced cull bull and open female sales. The costs for each breeding program were calculated. Costs for FTAI program include drug costs (prostaglandin, GnRH), CIDR and supplies (syringes, needles, applicator), semen (1 straw/cow), fee and mileage for AI technician, additional labour, clean up bull 
annual maintenance cost and handling system depreciation. Costs for the NSB program included costs to maintain a breeding bull year-round. All dollar values expressed are in Canadian dollars (\$CAN).

\subsection{Cost of Breeding Bull}

Bull maintenance costs were incurred for both FTAI and NSB programs and are shown in Table 1. Costs were based on assumptions for feed, bedding, mineral, grazing, vaccinations, breeding soundness evaluation, yardage, depreciation and $15 \%$ risk of loss following the approach described by Larson (2010). Bulls were assumed to graze for $180 \mathrm{~d}$ at a cost of $\$ 0.90 / \mathrm{d}$ as per private pasture rates reported by Hoimyr and Thompson (2013). Grass-legume hay $(20 \mathrm{~kg} / \mathrm{d} \times \$ 65 /$ tonne $)$ was assumed to be fed for $185 \mathrm{~d}$ and rolled barley $(3 \mathrm{~kg} / \mathrm{d} \times \$ 170 /$ tonne $)$ for $120 \mathrm{~d}$, and bedding straw was assumed to cost $\$ 15$ per head. Yardage was valued at $\$ 1.17$ per winter feeding day according to published cost of production benchmarks for 2012 Saskatchewan cow-calf producers (Larson, 2013). Vaccinations for bovine respiratory disease, blackleg, anthrax and footrot were estimated to cost $\$ 20$ per head (Larson, 2017).

Table 1. Annual bull maintenance costs

\begin{tabular}{cll}
\hline Direct Costs & Total $(\$)$ & Assumptions \\
\hline Hay & 245.41 & Fed $20 \mathrm{~kg} / \mathrm{d}$ for $185 \mathrm{~d}$, valued at $\$ 65 /$ tonne \\
Pasture & 162.00 & Grazing for $180 \mathrm{~d}$, valued at $\$ 0.90 /$ head/day \\
Bedding & 15.00 & Source: WBDC Fact Sheet $2014-04$ \\
Grain & 64.76 & Fed $3 \mathrm{~kg} / \mathrm{d}$ for $120 \mathrm{~d}$, valued at $\$ 170 /$ tonne \\
Minerals/salt & 15.00 & Source: Larson 2010 \\
Vet/medicine & 20.00 & Source: Larson 2010 \\
$\quad$ Semen testing & 100.00 & Source: Watrous Animal Hospital, 2015 \\
& 622.17 & \\
Yardage & 216.45 & $\$ 1.70$ per day $\times 185 \mathrm{~d}($ Larson 2013$)$ \\
Bull depreciation & 685.81 & Purchase Price $(\$ 4,000)$-Salvage value $(\$ 1.05 \times 842 \mathrm{~kg})$ divided by $3 \mathrm{yr}$ of use \\
Risk of loss & 600.00 & $15 \% \times$ purchase price \\
TOTAL $(\$)$ & $2,124.43$ & \\
\$/cow & 84.98 & 25 cows serviced per bull \\
\hline
\end{tabular}

The bull breeding soundness evaluation was estimated to cost $\$ 100$ per sire, which is similar to western Canadian veterinarian pricing accessed in 2015. The average price paid for breeding bulls between 2011 and 2013 at the Termuende Research Ranch was $\$ 4,000$ per bull. Herd culling records indicated bulls are typically culled after three years of use, with the average cull weight being $842 \mathrm{~kg}$ and cull price reported by Canfax (September, 2013) was $\$ 2.30$ per kilogram. The annual maintenance, risk and depreciation costs totaled $\$ 2,124$, which can be spread over the number of females the bull is expected to breed (Table 1). For the NSB program, each bull was expected to service 27 females ( 80 cows divided by 3 bulls), therefore the cost is $\$ 78.68$ per female exposed. In the FTAI program, each bull was expected to service 40 females, therefore the cost is $\$ 53.11$ per female exposed.

\subsection{Fixed-Time Artificial Insemination Costs}

Fixed time artificial insemination is a time-sensitive, labour intensive breeding method, and requires each cow move through a handling system three times over a 10 day timeline. The first time is for CIDR insertion and GnRH injection, a second time for CIDR removal and prostaglandin injection, and a third time for artificial insemination and a second dose of GnRH. For the purposes of the analysis, it was assumed two people averaged five minutes per cow to move the cows from the pen, handle each animal in a squeeze chute and return to the pen facility. Labour was valued at $\$ 18$ per hour for a cost of $\$ 9$ per cow. A trained technician performed the AI at a cost of $\$ 17.86$ per female. The CIDR cost was $\$ 17$ per cow, while drugs, syringe and needle costs were $\$ 12.19$, and semen cost at $\$ 26.60$ per straw, for a total cost of $\$ 55.79$ for FTAI supplies. The requirement of a handling system and sorting pens means a depreciation expense should be factored into the analysis. Infrastructure depreciation ( $\$ 1.33$ per chute run $\times 3=\$ 4.00$ per female) was based on an initial investment of $\$ 40,000,20 \mathrm{yr}$ life expectancy ( $5 \%$ annual decline in value), 300 head herd and five handling system times per animal per year. The cost of the clean-up bull $(\$ 2,124$ per year) was borne by all the females in the FTAI program $(n=40)$, for a cost of $\$ 53.11$ per female. The total cost for the FTAI program was $\$ 139.76$ per female. 
Average breeding program production was calculated as the total production of all calves whose dams were classified in a particular breeding program. Weaned calf revenue was calculated as follows; Calf revenue $(\$) /$ program $=$ Calf cumulative wean BW, $\mathrm{kg} /$ program $\times \mathrm{WCP}, \$ / \mathrm{kg}$, where, $\mathrm{WCP}=$ wean $249.4 \mathrm{~kg}(550 \mathrm{lb})$ calf prices. The 10 year (2008-2017) average price for weaned calves in Saskatchewan, Canada was $\$ 3.68 / \mathrm{kg}$ (Canfax 2017).

\subsection{Statistical Analysis}

Data (reproductive metrics, cow weight, Julian d of calving, calf birth weight, calf weaning age and weight, 205 $\mathrm{d}$ adjusted weaning weight) were analyzed using the MIXED procedure of SAS 9.2 (SAS 2003). The model used for the analysis was: $\mathrm{Y}_{\mathrm{ij}}=\mu+\mathrm{T}_{i}+\mathrm{e}_{i j}$, where, $\mathrm{Y}_{i j}$ was an observation of the dependent variable $i j ; \mu$ was the population mean for the variable; $\mathrm{T}_{i}$ was the fixed effect of the contemporary cow breeding program (NSB and FTAI); and $\mathrm{e}_{i j}$ was the random error associated with the observation $i j$. Cow was considered an experimental unit. For all statistical analyses, significance was declared at $P<0.05$.

\section{Results and Discussion}

\subsection{Cow Reproductive Performance}

The success of AI programs depends on using good quality semen and acceptable conception rates can be achieved with animals receiving adequate nutrition during the breeding season (Sudano et al., 2012). Beef cow reproductive performance in the NSB and FTAI programs is presented in Table 2. Body weight and body composition have important effects on cow reproductive efficiency and reflect the adequacy of the cow's energy reserves necessary for optimum reproductive performance (Houghton et al., 1990). At pregnancy diagnosis, no differences $(P=0.82)$ were observed among breeding programs for cow BW $(659 \pm 7.8 \mathrm{~kg})$, whereas FTAI program had greater $(P=0.03)$ cow BCS $(2.62$ vs. 2.52$)$, compared to average BCS for cows in NSB program.

Table 2. Effect of natural breeding (NSB) versus CO-Synch + controlled internal drug release (FTAI) on cow reproductive performance for 40 -cow herd

\begin{tabular}{|c|c|c|c|}
\hline \multirow{2}{*}{ Item } & \multicolumn{2}{|c|}{ Breeding program } & \multirow{2}{*}{$P$-value } \\
\hline & NSB & FTAI & \\
\hline$n$ & 40 & 40 & - \\
\hline Pregnancy diagnosis BW (kg) & $657 \pm 12$ & $661 \pm 9$ & 0.82 \\
\hline Pregnancy diagnosis BCS & 2.52 & 2.62 & 0.03 \\
\hline Pregnancy rate ( $\%$ of total cow) & 92.5 & 97.5 & 0.05 \\
\hline Pregnancy rate by AI (\% of total cow) & - & 58.0 & - \\
\hline Calving span $(\mathrm{d})$ & 69 & 64 & - \\
\hline Calving rate $(\%)$ & 80.0 & 92.5 & - \\
\hline Calf birth weight (kg) & $38.8 \pm 1.1$ & $40.1 \pm 0.72$ & 0.34 \\
\hline \multicolumn{4}{|l|}{ Calving distribution ( $\%$ of total calves) } \\
\hline $1-21 \mathrm{~d}$ & 43.8 & 62.2 & $<0.01$ \\
\hline $22-42 \mathrm{~d}$ & 47.0 & 21.6 & $<0.01$ \\
\hline $43-63 d$ & 9.4 & 16.2 & $<0.01$ \\
\hline
\end{tabular}

Note. $\mathrm{NSB}=$ natural service breeding $(\mathrm{NSB}) ; \mathrm{FTAI}=\mathrm{CO}$-Synch + controlled internal drug release; Cow $\mathrm{BW}$ adjusted for conceptus gain according to NRC (2000) recommendations; BCS = body condition score $(1=$ emaciated; 5 = obese; Lowman et al., 1976); Percentage of cows that conceived by artificial insemination.

In general as pointed out by Selk et al. (1988), the negative effects on cow reproduction (i.e., pregnancy rate) occur only when BCS drops below 2.5 (4.0 BCS, US scale) during the pre-calving and pre-breeding periods. Therefore, these performance results suggest cows in both breeding programs performed well and were in acceptable BCS $(>2.5)$ by the end of the breeding period.

There were four open (non-pregnant) cows in total, where FTAI and NSB programs had 1 and 3 open cows, respectively. Consequently, the FTAI program (AI pregnancy rate $=58 \%$; AI + clean-up bull pregnancy rate $=$ $97.5 \%$ ) had a slightly greater (5\%) pregnancy rate, compared to the NSB program. The current study pregnancy rates for NSB program were slightly lower than reported by Durunna et al. (2014), who reported pregnancy rates of $95.4 \%$ for winter calving cows. Nielson and Funston (2016) collected data from published studies reporting 
$\mathrm{AI}$ and final pregnancy rates and summarized final pregnancy rate following estrus synchronization and $\mathrm{AI}$ for a lower bull:cow ratio than the current study $(1: 50)$ was 89.2 percent (AI pregnancy rate $=55.6 \%$ ). Compared to the AI pregnancy rate reported by Nielson and Funston (2016), the pregnancy rate of FTAI cows in the current study $(97.5 \%)$ was slightly higher.

The overall rate of twinning was $2.5 \%$, with cows in NSB program having two twin births. Breeding program had no effect $(P=0.34)$ on calf birth weight between NSB $(39 \mathrm{~kg})$ and FTAI $(40 \mathrm{~kg})$ cows. Calf birth weights in the current study were lower compared to birth weight reported by Damiran et al. (2016) $(41.4 \pm 0.6 \mathrm{~kg}$ ), in studies conducted at the same location.

The length of the calving season has important implications for cow-calf producers. A 60 to $80 \mathrm{~d}$ calving season is suggested to optimize labour during calving and to wean more uniform calves (Deutscher et al., 1991). One method for producers to reduce the length of the calving season is by imposing a shorter breeding season. The average length of calving season was $5 \mathrm{~d}$ shorter in FTAI (64 d) program, compared to the NSB (69 d) program. Pang et al. (1998) reported a calving span of $53 \mathrm{~d}$, which was shorter than that of the current study, presumably because of the shorter breeding season evaluated in their study. The recommended breeding season length is $63 \mathrm{~d}$, which results in a similar $63 \mathrm{~d}$ calving season length (BCRC, 2019). In addition, the average calving span reported in the 2017 Western Canadian Cow-Calf survey was $87 \mathrm{~d}$ indicating cows in the current study are performing at levels higher than typical commercial cow-calf operations (Larson, 2018). The FTAI program calving rate was $12.5 \%$ greater compared to the NSB program. The calving rates of both programs did not match the pregnancy rates, because two cows in each program aborted. The calving rates of the NSB program reported in the current study (80\%) are similar with Pang et al. (1998), who reported $82 \%$, but lower than those reported by Durunna et al. (2014), who reported a $94 \%$ calving rate. The pregnancy rate for cows in the NSB program are within the range of that reported by Damiran et al. (2016) $(93 \pm 3 \%)$, a study conducted at the same location (Lanigan, Saskatchewan, Canada). There was a marked difference between the NSB and FTAI breeding program on the proportion of cows calving in the first 21 days (43.8\% vs. 62.2\%), 22-42 days (47.0 vs. 21.6\%), and 43-63 days (9.4 vs. 16.2\%) (Table 2). This suggests that compared to natural service breeding, a potential advantage of a FTAI program is to have more calves born in the first 21 days of the calving season, which allows producers to market larger, more uniform groups of calves. Some studies have shown as much as a 10 to 17 day calf age advantage and $10 \mathrm{~kg}$ weight advantage for FTAI calves at weaning, a result of estrous synchronization (Bo et al., 2007). The recommended industry target is to have at least $60 \%$ of females calving within the first cycle (Jaeger et al., 2004). In the present study, the FTAI breeding program met this recommendation for calving distribution.

\subsection{Calf Wean Performance}

Calving date and actual weaning weight of calves are important measures for beef producers to collect (Damiran et al., 2018). Calf wean performance differed between breeding programs, as weaning rate for FTAI program cows was greater $(90 \%)$ compared to cows in the NSB program (77.5\%) (Table 3). The higher weaning rate of FTAI cows is partially due to the higher pregnancy rate achieved in this program $(97.5 v s .92 .5 \%)$ and partially due to lower abortion and calf death loss (FTAI program [1 open, 37 born, 36 weaned]; NSB program [3 open, 33 born, 31 weaned]). Cows bred in the FTAI program, weaned five more calves compared to cows bred in the NSB program. Calf survival to weaning is important to cow-calf producers because a higher percentage of weaned calves generates more income and provides more options for replacement selection (Bo et al., 2007).

Calf pre-weaning average daily gain (ADG) was lower $(P=0.02)$ for the calves from FTAI cows $(1.13 \mathrm{~kg} / \mathrm{d})$ compared to the calves born to cows in the NSB program $(1.21 \mathrm{~kg} / \mathrm{d})$. Breeding date differed between programs (June 24 vs. July 20, 2013, for NSB and FTAI, respectively), but the calves were weaned on the same date (October 5, 2014). Marshall et al. (1990) studied calving date and reported that calf birth weight and pre-wean ADG did not differ $(P>0.05)$ for calves born $21 \mathrm{~d}$ apart. The ADG for calves born to NSB cows was in the range with historical (2001 and 2017) pre-weaning ADG records $(1.07 \pm 0.17 \mathrm{~kg} / \mathrm{d})$ previously reported by Damiran et al. (2018) on the WBDC research cow herd. 
Table 3. Effect of natural breeding (NSB) versus CO-Synch + controlled internal drug release (FTAI) on calf weaning performance of 40 -cow herd

\begin{tabular}{|c|c|c|c|c|}
\hline \multirow{2}{*}{ Item } & \multicolumn{2}{|c|}{ Breeding program } & \multirow{2}{*}{ SEM } & \multirow{2}{*}{$P$-value } \\
\hline & NSB & FTAI & & \\
\hline Cow, $n$ & 40 & 40 & - & - \\
\hline Total weaned calves, $n$ & 31 & 36 & 0.61 & 0.42 \\
\hline Wean rate of calves $(\%)$ & 77.5 & 90 & 0.53 & 0.01 \\
\hline Pre-weaning ADG (kg/d) & 1.21 & 1.13 & 0.02 & 0.02 \\
\hline Calf age at weaning (Julian day) & 172.2 & 145.4 & 3.13 & $<0.01$ \\
\hline Calf weaning BW (kg) & 245.8 & 207.6 & 5.70 & $<0.01$ \\
\hline Calf adjusted 205-d weaning BW (kg) & 286.0 & 271.9 & 4.83 & 0.04 \\
\hline Calf cumulative weaning BW (kg) & 7636 & 7490 & - & - \\
\hline Calf cumulative adjusted 205-d wean BW (kg) & 8297 & 10192 & - & - \\
\hline
\end{tabular}

Note. NSB $=$ natural service breeding $(\mathrm{NSB}) ; \mathrm{FTAI}=\mathrm{Co}-\mathrm{Synch}+$ controlled internal drug release; Wean rate $(\%)$ $=[($ calves weaned $(\mathrm{n}) /$ cows exposed $(\mathrm{n})) \times 100] ; \mathrm{ADG}$ during birth to weaning period; Calf cumulative weaning $\mathrm{BW}=$ Calf wean $\mathrm{BW}(\mathrm{kg}) \times$ Total weaned calves per breeding program $(\mathrm{n})$.

Lower $(P=0.01)$ weaning weight for FTAI calves compared to NSB calves was largely attributed to younger age ( $26 \mathrm{~d} ; P=0.01)$ at weaning for the FTAI calves. However, when adjusted by breeding start difference, no difference $(P=0.16$; data not shown) was observed in WW between NSB calves $(245.8 \pm 5.7 \mathrm{~kg})$ and FTAI calves $(234.7 \pm 5.4 \mathrm{~kg}$ ). This is similar to Marshall et al. (1990), observing similar ADG of calves born 21 and $42 \mathrm{~d}$ apart. In addition, due to the lower $(P=0.01)$ pre-wean ADG, the FTAI program calves had lower $(5.3 \%) 205-\mathrm{d}$ adjusted weaning weights (271 vs. $286 \mathrm{~kg}$ ) compared to the NSB program calves. Although the FTAI program had more calves weaned, because of lower wean weight, FTAI program had lower (2\%) total cumulative weaned BW (7490 kg per $40 \mathrm{cow}$ ) compared to NSB cow program (7636 kg per $40 \mathrm{cow})$. However, the FTAI program calves had greater (23\%) total 205-d adjusted weaned weight compared to NSB program calves $(10,192 v s .8297$ $\mathrm{kg}$ for FTAI and NSB, respectively).

\subsection{Breeding Program Cost Evaluation}

Table 4 presents the costs associated with keeping breeding bulls and also summarizes the assumptions that have been made for these estimations. All dollar values expressed are in Canadian dollars (CAN\$).

Collected cost data and calculations from Larson (2010), were used for winter feed and grazing costs, yardage, veterinary/medical costs, purchase and cull prices, years of use and bull:cow ratio. Bull purchase price averaged $\$ 4000$, ranging from $\$ 2700$ to $\$ 5400$, with a risk of $15 \%$ of bulls being injured, and having to be replaced each year. The annual bull maintenance costs averaged $\$ 838$ per year. In 2014 , the cull bull sale (salvage value) price was $\$ 880$, and average number of years bulls used was $3 \mathrm{yr}$, therefore bull depreciation calculated to be $\$ 685.81$. The average annual cost for a bull was $\$ 2124$ for 40 -cow herd scenario. Dividing the total annual cost by 25 (number of cows, bull expected to service), the per cow cost of a bull equals $\$ 84.98$ per cow. The average bull to cow ratio for western Canada was reported to be 1:24 (Larson, 2018).

The costs associated with the FTAI program for a 40 cow herd are presented in Table 5. When the bull:cow ratio of $1: 40$ is used, the bull (clean-up) purchase price ( $\sim \$ 53 /$ cow; $38 \%$ of total cost), semen price ( $\sim 27 /$ cow; $19 \%$ of total cost), CIDR ( $\$ 17 / \mathrm{cow} ; 12 \%$ of total cost) price, and total AI technician cost ( $\$ 18.0 ; 13 \%$ of total cost) were the most prominent variables in determining FTAI costs. 
Table 4. Bull ownership/maintenance costs for natural service breeding (NSB) (40 cows)

\begin{tabular}{lll}
\hline Item & Cost $(\$)$ & Assumptions/Source \\
\hline Direct costs & & \\
$\quad$ Hay & 245.41 & Fed $20.4 \mathrm{~kg} / \mathrm{d}$ for 185 days, valued at $\$ 65 /$ ton \\
Pasture & 162.00 & On grass for 180 days; grazing worth $\$ 0.90 /$ bull/day \\
Bedding & 15.00 & Source: Larson $(2010)$ \\
$\quad$ Grain & 64.76 & Fed 3.2 kg/d for 120 days, valued at $\$ 170 /$ ton \\
$\quad$ Minerals/Salt & 15.00 & Source: Larson $(2010)$ \\
$\quad$ Vet/Medicine & 20.00 & Source: Larson $(2010)$ \\
$\quad$ Semen testing & 100.00 & - \\
Total direct costs & 622.17 & - \\
Yardage cost & 216.45 & $\$ 1.17$ per day $\times 185$ day (Larson 2012) \\
Bull depreciation & 685.81 & Based on actual average purchase price (\$4000) less salvage value (cull bull sale price in \\
& & $2014=\$ 1.05 \times 839$ kg) divided by 3 years of use (Average number of years bulls used) \\
Risk of bull loss & 600.00 & $15 \%$ of bulls will need to be replaced during breeding season \\
Total costs & $2,124.43$ & - \\
\$/cow (25 cows) & 84.98 & - \\
\hline
\end{tabular}

Overall total breeding costs for the 40 -cow herd were $\$ 5,591$ hence, the average cost per cow was $\$ 140$. Thus, the cost for pregnancy of each cow was greater (by $\sim \$ 55$; or by $65 \%$ ). These results agree with Johnson and Jones (2008), who reported that if only the cost per pregnancy is considered, few AI programs consistently compete well with a natural service breeding, which is in agreement with the current study results. Johnson and Jones (2008) further suggested that thorough assessment of economic feasibility of estrus synchronization and AI should incorporate potential returns and account for the random nature of various inputs and economic risk in the decision making process.

Table 5. Cost of fixed-time artificial insemination program (FTAI) for 40 herd

\begin{tabular}{|c|c|c|}
\hline Item & Total $(\$)$ & $\$ /$ cow \\
\hline \multicolumn{3}{|l|}{ FTAI supplies } \\
\hline Prostaglandin & 207.48 & 5.19 \\
\hline GnRF (2 doses) & 243.45 & 6.09 \\
\hline CIDR & 680.11 & 17.00 \\
\hline Syringes, applicator & 36.67 & 0.92 \\
\hline Semen & $1,064.00$ & 26.60 \\
\hline Total supply costs & $2,231.70$ & 55.79 \\
\hline \multicolumn{3}{|l|}{ AI technician } \\
\hline AI fee & 420.00 & 10.50 \\
\hline Mileage & 119.28 & 2.98 \\
\hline Labour charge & 175.14 & 4.38 \\
\hline Total AI technician costs & 714.42 & 17.86 \\
\hline \multicolumn{3}{|l|}{ Ranch labour } \\
\hline Ranch labourers & 120.00 & 3.00 \\
\hline \multicolumn{3}{|l|}{ Clean up bull } \\
\hline Clean up bull & $1,699.55$ & 42.49 \\
\hline \multicolumn{3}{|l|}{ Overhead } \\
\hline Handling system & 160.00 & 4.00 \\
\hline Total costs & $4,925.67$ & 123.14 \\
\hline
\end{tabular}

Note. AI technician cost $=$ AI technician and supplied semen; Ranch labourers $=$ Two staff at $\$ 18 /$ hour, 5 mins $/$ cow $\times 3$ chute runs; Cleanup bull $=$ Achieve $50 \%$ conception with AI (20 natural service at $\$ 84.98 / \mathrm{cow}$ ); Handling system $=$ Assume $\$ 40,000$ (5\% depreciation) on handling system required infrastructure for FTAI. 
For calculated weaned calf revenue, the FTAI program generated an additional $\$ 6957$ per year (Figure 2). This represents a large financial advantage for cow-calf producers. Overall, the differences in average production between the programs in the current study was associated with differences in total number of calves weaned and higher total kg weaned (205-d adjusted basis), but some differences may be associated with calf weaning weight.

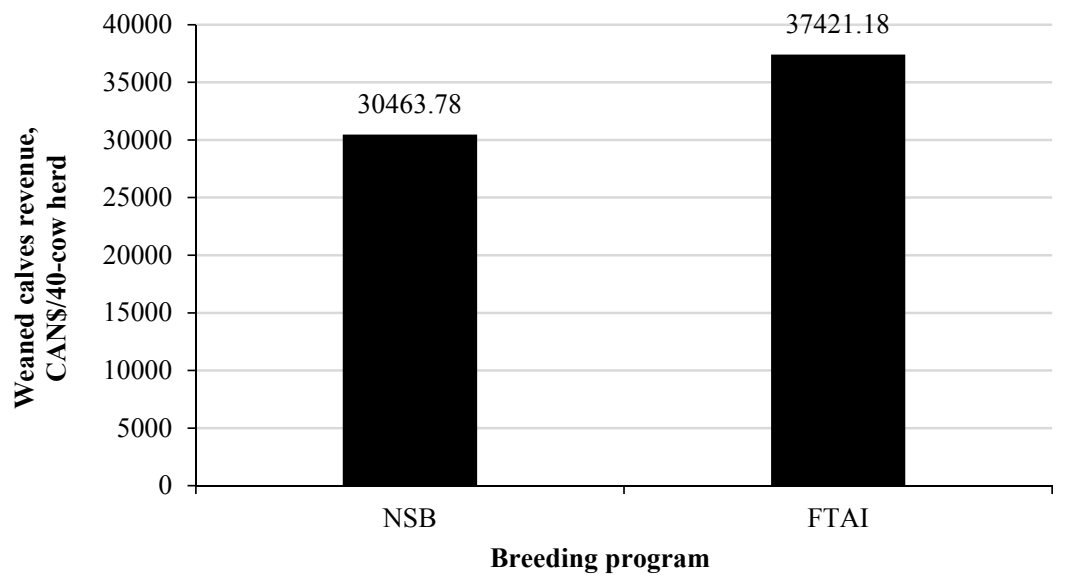

Figure 2. Effect of breeding system on weaned calf revenue.

Note. NSB = natural service breeding; FTAI = fixed time artificial insemination. Revenue calculated as calf cumulative $\mathrm{kg}$ (205 d adjusted wean weight) of 40-cow herd $\times$ estimated market value of $\$ 3.68$ per $\mathrm{kg}$ (2008-2017 average price for $249.4 \mathrm{~kg}$ calf in Saskatchewan).

In western Canada, the cost of production is reported at $\$ 962$ per cow wintered (Alberta Agriculture and Forestry 2016). Consequently, weaned calf revenue per cow was $\$ 983$ and $\$ 1011$ for the NSB and FTAI programs, respectively. Therefore, in terms of weaned calf revenue, FTAI program generated greater return compared to the NSB program. Thus, the present study findings demonstrate the potential for cow-calf producers to use artificial insemination.

However, a partial budget is simply an analysis tool that may not address all costs accrued on the ranch, only the costs and revenues that will change if the management practice being considered is implemented. A partial-budget analysis comparison for fixed-time artificial insemination with natural service breeding is presented in Table 6 .

In the partial budget analysis, the advantages from integrating the new program (increased revenues and decreased costs) are compared against any disadvantages (decreased revenues and increased costs). The disadvantages are then subtracted from the advantages to give the net change in profit from the management practice being considered. Table 6 shows increased costs associated with the 7-d CO-Synch + CIDR (FTAI) protocol including semen, AI technician, facilities costs and labour. 
Table 6. Partial budget comparison for FTAI vs. NSB breeding programs for 40 cow herd

\begin{tabular}{cl|cl}
\hline Increased costs & $\$$ & Increased revenue & $\$$ \\
\hline Drugs, CIDR, supplies & 1,168 & Change in wean weight & $-10.4 \mathrm{~kg} / \mathrm{calf}$ \\
Semen costs & 1,064 & Change in wean rate $(\%)$ & $12.5 \%$ \\
AI technician & 714 & Value of additional kg & $\$ 12,090$ \\
Chute runs/labour & 120 & & \\
Total increased costs & 3,066 & Total increased revenue & 12,090 \\
\hline Reduced revenue & $\$$ & Reduced costs & $\$$ \\
\hline Reduced cull bull sales & 660 & Fewer bulls required & 2,124 \\
Fewer open cull sales & 1,938 & Fewer replacements required & 2,800 \\
Total decrease in profits & 5,664 & Total increase in profits & 17,014 \\
\hline
\end{tabular}

Net change in profits $=\$ 11,350$

Note. NSB $=$ natural service breeding; FTAI $=$ Co-Synch + controlled internal drug release; Partial budget adapted from Mississippi State University Extension Service (Publication \#2486); Wean weight $=205 \mathrm{~d}$ adjusted weaning weights.

The decreased revenues resulting from fewer bulls required if a FTAI program is implemented (assume 50\% fewer bulls) and fewer non-pregnant cows for cull sales resulting from increased conception rate. Increased revenues are generated from increases in conception rate, weaning rate and weaning weight. Reduced costs are a result from requiring fewer herd sires (estimate $50 \%$ of cows bred $\mathrm{AI}$ ) and $5 \%$ fewer replacements valued at CAN $\$ 1400$ per cow. Overall, for the 40-cow herd scenario, net change in profit due to FTAI implementation was $\$ 11,350$ dollars.

Implementing a FTAI breeding program, reduces the number of natural service bulls required and thereby lowers bull ownership expenditures. At the time of this comparison, bull prices were relatively low. Any change in feed prices would also certainly impact the expenditure categories. Increases in bull purchase price and hay costs could further increase the advantage of using a FTAI program. These costs of supplemental feed would also have an impact on the relative advantage of the FTAI program. Moreover, as the herd size increases on a beef operation, the FTAI program is more likely to have lower costs compared to a natural service breeding program (Johnson \& Jones, 2008). Total beef cow herd in Canada is $\sim 4$ million (Statistics Canada, 2017), and average beef cow herd size in Canada is 63 animals. However, 63, 24, and 13\% of the producers have $>47,47$ to 122 , and $<122$ cows (Statistics Canada, 2011), which would suggest that a FTAI program is more economically attractive to Canadian beef industry. Furthermore, when a reduced bull-to-cow ratio is maintained, for the NSB program, the FTAI program advantage value would also become more positive. In agreement with the current study findings, Johnson and Jones (2008) also noted that estrus synchronization and artificial insemination were economically advantageous compared with natural service when a sufficient genetic value premium could be obtained from AI sired calves. In conclusion, the 2015 Canadian National Beef Strategy has a target to increase production efficiency by $15 \%$ by the year 2020 (Canadian National Beef Strategy, 2015). Utilization of superior genetics through the selection of high merit AI sires and fixed-time artificial insemination can aid in the achievement of this target.

\section{Conclusions}

As evidenced by the results of the current study, from the point of the view of the cost for pregnancy, the natural service program can be a lower cost (less by $\sim \$ 38 / \mathrm{cow}$ ) option compared to the FTAI program. However, considering improvements in conception rate, calving span, calving rate, calving distribution, calf weaning rate and weights in a partial budget analysis, FTAI generated $\$ 11,350$ (\$284 per cow) net increase in profit, which would make a FTAI program worth considering by commercial beef producers. Nevertheless, producers should critically evaluate their own operation to determine which type of breeding program to use, taking into account their own production costs, expected AI conception rates, need for improved genetics, and management capabilities.

\section{Acknowledgements}

This work was supported by grants from Saskatchewan Agriculture Demonstration of Practices and Technologies (20120423) and the Western Beef Development Centre. The authors thank the staff at Western Beef Development Centre's Termuende Research Ranch for sampling and technical assistance. 


\section{References}

Alberta Agriculture and Forestry. (2016). AgriProfit\$ Multi-year economic, productive and financial performance of Alberta cow/calf operations. Retrieved from http://www1.agric.gov.ab.ca/\$department/ deptdocs.nsf/all/econ8479

BCRC (Beef Cattle Research Council). (2019). Adoption rates of recommended practices by cow-calf operators in Canada. Retrieved July 30, 2019, from http://www.beefresearch.ca

Bó, G. A., Cutaia, L., Peres, L. C., Pincinato, D., Maraña, D., \& Baruselli, P. S. (2007). Technologies for fixed-time artificial insemination and their influence on reproductive performance of Bos indicus cattle. Society for Reproduction \& Fertility, 64, 223-236. https://doi.org/10.5661/RDR-VI-223

Canadian National Beef Strategy. (2015). Canadian National Beef Strategy 2015-2020. Retrieved August 28, 2019, from http://beefstrategy.com/pdf/National-Beef-Strategy-2-page\%20summary.pdf

CANFAX. (2017). Canfax 2017 Annual Report (p. 34). Calgary, Alberta Canada. Retrieved from http://www.canfax.ca/SampleReports.aspx

CCAC (Canadian Council on Animal Care). (2009). CCAC guidelines on: The care and use of farm animals in research, teaching and testing. CCAC, Ottawa, Canada. Retrieved July 24, 2019, from http://www.ccac.ca/ Documents/Standards/Guidelines/Farm_Animals.pdf

Damiran, D., Lardner, H. A., Larson, K., \& McKinnon, J. (2016). Effects of supplementing spring-calving beef cows grazing barley crop residue with canola meal and wheat-based dry distillers' grains with solubles on performance, reproductive efficiency, and system cost. Professional Animal Scientist, 32, 400-410. https://doi.org/10.15232/pas.2015-01479

Damiran, D., Larson, K., Pearce, L., Erickson, N., \& Lardner, H. A. (2018). Effect of calving period on beef cow longevity and lifetime productivity in western Canada. Sustainable Agricultural Research, 7, 11-17. https://doi.org/10.5539/sar.v7n4p11

DeRouen, S. M., Franke, D. E., Morrison, D. G., Wyatt, W. E., Coombs, D. F., White, T. W., ... Greene, B. B. (1994). Prepartum body condition and weight influences on reproductive performance of first-calf beef cows. Journal of Animal Science, 72, 1119-1125. https://doi.org/10.2527/1994.7251119x

Deutscher, G. H., Stotts, J. A., \& Nielsen, M. K. (1991). Effects of breeding season length and calving season on range beef cow productivity. Journal of Animal Science, 69, 3453-3460. https://doi.org/10.2527/ $1991.6993453 x$

Durunna, O. N., Girardin, L. C., Scott, S. L., Robins, C., Block, H. C., Iwaasa, A. D., ... Lardner, H. A. (2014). The effects of spring versus summer calving on beef cattle reproductive and growth performance in western Canada. Canadian Journal of Animal Science, 94, 259-271. https://doi.org/10.4141/CJAS2013-180

Hoimyr, L., \& Thompson, L. (2013). Forage Market Price Discovery in Saskatchewan (p. 24). Saskatchewan Forage Council.

Houghton, P. L., Lemenager, R. P., Moss, G. E., \& Hendrix, K. S. (1990). Prediction of postpartum beef cow body composition using weight to height ratio and visual body condition score. Journal of Animal Science, 68, 1428-1437. https://doi.org/10.2527/1990.6851447x

Jaeger, J. R., Pirelli, G. J., \& Weber, D. W. (2004). Beef Cow-Calf Management Guide (p. 20, EM 8827). Oregon State University Extension Service.

Johnson, S. K., \& Jones, R. D. (2008). A stochastic model to compare breeding system costs for synchronization of estrus and artificial insemination to natural service. Professional Animal Scientist, 28, 588-595. https://doi.org/10.15232/S1080-7446(15)30403-4

Kelln, B. M., Lardner, H. A., McKinnon, J. J., Campbell, J. R., Larson, K., \& Damiran, D. (2011). Effect of winter feeding system on beef cow performance, reproductive efficiency and system cost. Professional Animal Scientist, 27, 410-421. https://doi.org/10.15232/S1080-7446(15)30513-1

Krause, A. D., Lardner, H. A., McKinnon, J. J., Hendrick, S., Larson, K., \& Damiran, D. (2013). Comparison of grazing oat and pea crop residue versus feeding grass- legume hay on beef-cow performance, reproductive efficiency, and system cost. Professional Animal Scientist, 29, 535-545. https://doi.org/10.15232/S10807446(15)30275-8 
Lardner, H. A., Damiran, D., Hendrick, S., Larson, K., \& Funston, R. (2014). Effect of development system on growth and reproductive performance of beef heifers. Journal of Animal Science, 92, 3116-3126. https://doi.org/10.2527/jas.2013-7410

Larson, J. E., Lamb, G. C., Stevenson, J. S., Johnson, S. K., Day, M. L., Geary, T. W., ... Arseneau, J. D. (2006). Synchronization of estrus in suckled beef cows for detected estrus and artificial insemination and timed artificial insemination using gonadotropin-releasing hormone, prostaglandin F2 $\alpha$, and progesterone. Journal of Animal Science, 84, 332-342. https://doi.org/10.2527/2006.842332x

Larson, K. A. (2010). What is the cost of the herd sire? (p. 4, WBDC Fact Sheet \#2010-04). Western Beef Development Centre, Lanigan, Saskatchewan, Canada.

Larson, K. A. (2013). 2012 Saskatchewan cow-calf cost of production analysis (p. 4, WBDC Fact Sheet \#2013-04). Western Beef Development Centre, Lanigan, Saskatchewan, Canada.

Larson, K. A. (2017). Value of vaccination (p. 4, WBDC Fact Sheet \#2017-03). Western Beef Development Centre, Lanigan, Saskatchewan, Canada.

Larson, K. A. (2018). 2017 western Canadian cow-calf survey aggregate results (p. 31, Final report). University of Saskatchewan. Retrieved from http://westernbeef.org/pdfs/wcccs/2017_WCCCS_Summary-FINAL.pdf

Lowman, B. G. N., Scott, N. A., \& Sommerville, S. H. (1976). Condition scoring for cattle (Bulletin No. 6, p. 31). East of Scotland College of Agriculture, Edinburgh School of Agriculture, Edinburgh, Scotland, UK.

Lucy, M. C., Billings, H. J., Butler, W. R., Ehnis, L. R., Fields, M. J., Kesler, D. J., ... Hafs, H. D. (2001). Efficacy of an intravaginal progesterone insert and an injection of PGF $2 \alpha$ for synchronizing estrus and shortening the interval to pregnancy in postpartum beef cows, peripubertal beef heifers and dairy heifers. Journal of Animal Science, 79, 982-995. https://doi.org/10.2527/2001.794982x

Marshall, D. M., Minqiang, W., \& Freking, B. A. (1990). Relative calving date of first-calf heifers as related to production efficiency and subsequent reproductive performance. Journal of Animal Science, 68, 1812-1817. https://doi.org/10.2527/1990.6871812x

Martinez, M. F., Kastelic, J. P., Adams, G. P., Cook, B., Olson, W. O., \& Mapletoft, R. J. (2002). The use of progestins in regimens for fixed-time artificial insemination in beef cattle. Theriogenology, 57, 1049-1059. https://doi.org/10.1016/S0093-691X(01)00682-3

Meneghetti, M., Sá Filho, O. G., Peres, R. F. G., Lamb, G. C., \& Vasconcelos, J. L. M. (2009). Fixed-time artificial insemination with estradiol and progesterone for B. indicus cows I: Basis for development of protocols. Theriogenology, 72, 179-189. https://doi.org/10.1016/j.theriogenology.2009.02.010

Nielson, H., \& Funston, R. N. (2016). How many clean-up bulls are needed after estrus synchronization and artificial insemination? Nebraska Beef Cattle Report 9. Retrieved August 23, 2019, from https://beef.unl.edu/documents/2016-beef-report/2-2016-Clean-up-Bulls-after-Estrus-Synchronization-Artif icial-Insemination.pdf

NRC (National Research Council). (2000). Nutrient requirements of beef cattle (7th ed.). The National Academy Press, Washington, DC.

Pang, H. M., Makarechian, M., Goonewardene, L. A., \& Berg, R. T. (1998). Effects of early versus late spring calving on beef cow-calf productivity. Canadian Journal of Animal Science, 78, 249-255. https://doi.org/ 10.4141/A97-113

Parish, J. A., \& Riley, J. M. (2011). Economic comparisons of artificial insemination vs. natural mating for beef cattle herds (Publication 2486). Mississippi State University Extension Service. Retrieved from July 24, 2019, https://extension.msstate.edu/sites/default/files/publications/publications/p2486_1.pdf

Pursley, J. R., Wiltbank, M. C., Stevenson, J. S., Ottobre, J. S., Garverick, H. A., \& Anderson, L. L. (1997). Pregnancy rates per artificial insemination for cows and heifers inseminated at a synchronized ovulation or synchronized estrus. Journal of Dairy Science, 80, 295-300. https://doi.org/10.3168/jds.S0022-0302(97) 75937-X

Reiling, B. A. (2011). Standard calculation and interpretation of basic cow herd performance measures. Nebraska Extension Bulletin, G2094 (p. 4). Retrieved September 20, 2019, from http://extensionpublica tions.unl.edu/assets/html/g2094/build/g2094.htm\#target3

SAS Institute Inc. (2003). SAS User's Guide: Statistics (Version 9.2, 8th ed.). SAS Inst., Inc., Cary, NC. 
Selk, G. E., Wettemann, R. P., Lusby, K. S., Oltjen, J. W., Mobley, S. L., Rasby, R. J., \& Garmendia, J. C. (1988). Relationships among weight change, body condition and reproductive performance of range beef cows. Journal of Animal Science, 66, 3153-3159. https://doi.org/10.2527/jas1988.66123153x

SMA (Saskatchewan Ministry of Agriculture). (2009). Farm machinery custom and rental rate guide, 2008-2009. Regina, Saskatchewan, Canada.

Statistics Canada. (2011). Census of agriculture. Retrieved September 12, 2019, from http://www.statcan.gc.ca/ ca-ra2011/indexeng.htm

Sudano, M. J., Crespilho, A. M., Fernandes, C. B., Martins Junior, A., Papa, F. O., Rodrigues, J., ... Landim-Alvarenga, F. C. (2011). Use of Bayesian inference to correlate in vitro embryo production and in vivo fertility in Zebu bulls. Veterinary Medicine International, 8, 1-6. https://doi.org/10.4061/2011/436381

Tigner, R. (2018). Partial Budgeting: A Tool to Analyze Farm Business Changes. Ag Decision Maker (File C1-50). Iowa State University. Retrieved September 9, 2019, from https:/www.extension.iastate.edu/agdm/ wholefarm/pdf/c1-50.pdf

\section{Copyrights}

Copyright for this article is retained by the author(s), with first publication rights granted to the journal.

This is an open-access article distributed under the terms and conditions of the Creative Commons Attribution license (http://creativecommons.org/licenses/by/4.0/). 